\title{
Mining rules of decision-making for fleet composition under market uncertainty using a genetic algorithm
}

\author{
Kazuo Hiekata $^{1} \cdot$ Shinnosuke Wanaka ${ }^{2} \mathbb{D} \cdot$ Yoshinori Okubo $^{1}$
}

Received: 15 April 2021 / Accepted: 4 December 2021 / Published online: 18 January 2022

(c) The Author(s) 2022

\begin{abstract}
This study proposes a method for determining decision-making rules on fleet composition that are effective from a perspective of profitability in the shipping industry, where there are several market uncertainties such as fuel prices, freight rates, exchange rate, transportation demand, world transportation capacity, and ship price. A simulator is used to calculate the revenue of the fleet composition based on the market scenario. Using this to optimize the buying and selling behavior of ships, decision-making rules regarding fleet composition can be determined. The rules are expressed as a vector, and a genetic algorithm (GA) is used for optimization. As a case study, the method was applied to container ships operating between Asia and Europe. The simulation revealed optimal decision-making rules. Moreover, a controlled experiment was conducted to validate the effectiveness of the rules. Participants were randomly divided into two groups: those with rules and those without rules, and they were asked to perform buying and selling behavior in a simulated environment. By comparing these groups' profits, it is validated that the rules discovered by the method are useful because they encourage decision-making from a long-term perspective.
\end{abstract}

Keywords Maritime fleet size and mix problem $\cdot$ Shipping market simulation $\cdot$ Genetic algorithm

\section{Introduction}

The shipping industry is highly dynamic and has various market cycles: long-term cycles driven by major changes in the industry, short-term cycles driven by the evolution and fluctuation of the world economy, and seasonal cycles, which are characteristic of commodity trades by ships [1]. It is difficult to forecast the future market, and shipping companies always need to operate their fleet under uncertainty. Although the industry has many uncertainties, interviews [2] with three Japanese shipowners revealed that they do not have a technical method for forecasting ship demand and rely on decision-making based on their intuition and

Shinnosuke Wanaka

wanaka-s@m.mpat.go.jp

1 Graduate School of Frontier Science, The University of Tokyo, 5-1-5, Kashiwanoha, Kashiwa, Chiba 277-0882, Japan

2 Knowledge and Data System Department, National Maritime Research Institute, 6-38-1, Shinkawa, Mitaka, Tokyo 181-0004, Japan experience. However, because the environment where ships are operated is highly changeable and uncertain, the intuition and experience learned from past cases are not always applicable for decision-making. There is a need to develop a data and model-based decision-making method for fleet composition that does not rely on intuition and experience.

This study proposes a method for revealing decisionmaking rules on fleet composition that are effective from a profitability perspective. A simulator is used to calculate the revenue of the fleet composition based on the market scenario. Using simulations to optimize the buying and selling behavior of ships enables the discovery of decisionmaking rules regarding fleet composition. As a case study, the method was applied to container ships operating between Asia and Europe. Moreover, a controlled experiment was conducted, and it demonstrates the usefulness of the rules.

\section{Literature review}

One of the traditional problems in the shipping industry is the maritime fleet size and mix problem (MFSMP), in which how many vessels to utilize to meet shipping demand is 
decided. Everett et al. [3] utilized linear programming (LP) to optimize fleets of bunkers and tankers for carrying $15 \%$ of US international trade in dry and liquid commodities. Murotsu and Taguchi [4] built a mathematical model relating to the fleet's transportation cost and proposed a method to optimize the fleet composition by combining dynamic programming (DP) and non-linear programming to minimize the cost. Zeng and Yang [5] described not only the determination of the types of ships and the number of each type but also optimization of the routing to minimize the total cost. A simulation approach was also utilized to evaluate and compare multiple fleets. Darzentas and Spyrou [6] developed a simulation of ferry traffic to evaluate passenger delays, the number of ships in queue at ports, and so on. By changing the fleet composition, they compared the indexes to design.

Research related to the MFSMP mainly focuses on the design of the overall fleet size and mix of vessel type for a static shipping demand and does not consider fleet change to meet a dynamic demand over time. However, once the fleet composition has been determined, it must be updated in response to subsequent changes in demand. The fleet operator needs to make decisions such as buying, chartering, or scrapping vessels.

The maritime fleet renewal problem (MFRP) concerns a strategy for the fleet to meet the dynamic demand for some periods. Xie, Wang, and Chen [7] combined DP and LP to optimize the development strategy of the fleet over time. Meng and Wang [8] proposed a scenario-based DP model for a multi-period liner ship fleet planning method. They demonstrated that chartering ships may not always be a better policy for long-term planning compared to buying new ships. Jin and Kite-Powell [9] applied optimal control theory to decision-making for both fleet utilization and replacement to maximize profit. Alvarez et al. [10] proposed a mixedinteger programming model for multi-period fleet sizing and deployment decisions.

In summary, a number of studies have investigated the problem of determining an optimal fleet size and mix. MFSMP is the initial design problem to develop a fleet for short-term static demand, and MFRP is the exploration of long-term strategic operations to update the fleet. On the other hand, most studies do not address the issue of future uncertainty in the shipping market. Pantuso, Fagerholt, and Hvattum [11] suggested that uncertain market behavior is an important characteristic of the problem to consider, and future research needs to focus on the renewal of the fleet where the continual adaptation of the fleet to changes in the market situation is required. Real option analysis is an effective tool for overcoming these uncertainties [12], and the development of a strategic decision-making method that considers future market uncertainty is still a problem to solve.
A genetic algorithm (GA) has been utilized in many other domains to find a decision-making rule under uncertainty. Fidelis, Lopes, and Freitas [13] introduced a classification algorithm based on a GA that discovers human-understandable if-then-style rules. The usefulness of the algorithm was assessed on two public domain datasets of dermatology and breast cancer. Kim and Han [14] proposed a data mining method based on GAs to discover bankruptcy decision rules from experts' qualitative evaluation. In the experiments, the GA showed higher accuracy and greater coverage compared to inductive learning and neural networks. This demonstrated that the rules found using genetic algorithms were largely consistent with the experts' problem-solving knowledge. Several studies $[15,16]$ have attempted to improve shipping companies' profitability using rules to buy and sell ships based on past ship price patterns. They showed the usefulness of the rules; however, to the best of our knowledge, there is a lack of research on determining better rules using a mathematical method such as GA.

The novelty of the current research is that it focuses on the fleet composition problem under the market's future uncertainty and utilizes a GA to find decision-making rules for the problem. This study proposes a method to determine a strategic rule for decision-making to update the fleet, which considers the future uncertainty of the shipping market. As for market uncertainty, this study considers oil price, Japan-US exchange rate, ship price, freight rate, and shipping demand. By combining models considering these uncertainties and a GA, this research enables the determination of decision-making rules under uncertainties.

\section{Method of decision-making rule mining using genetic algorithm}

This section outlines a method to determine optimal decision-making rules for buying and selling ships (See Fig. 1).

The market model is used to create market simulation scenarios based on historical market data. Buy and sell rules are those for decision-making when a ship operating company

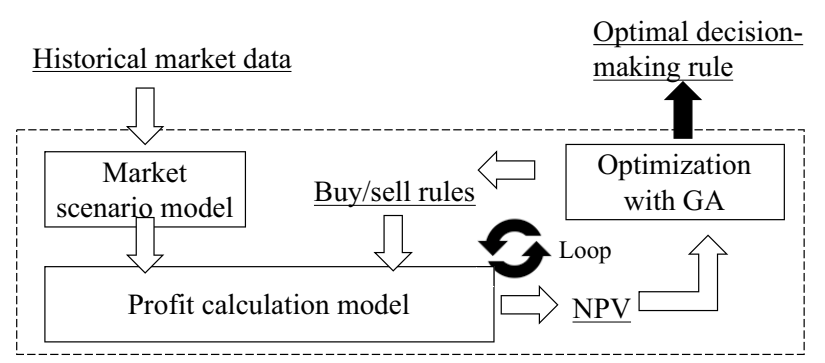

Fig. 1 Overview of a proposed method for decision-making rule mining using GA 
buys and sells ships and are vectored and expressed as a chromosome, a set of parameters and optimized in GA. The profit calculation model simulates operation for 15 years, which utilizes the market scenario and buy and sell rules, and outputs the net present value (NPV) of the operation. The GA utilizes this profit calculation and optimizes the chromosome to improve the NPV. Eventually, it is possible to obtain an optimal decision-making rule for fleet composition management. The rest of this section describes each detail of the market scenario model, the profit calculation model, and the optimization method with GA.

\subsection{Market scenario model}

To optimize the buy and sell rules for fleet composition, it is necessary to create a number of scenarios for the shipping market that contain future uncertainty and fluctuation. The market scenario model learns the parameters from historical market data and outputs many scenarios based on the parameters.

This model assumes the shipping market consists of fuel oil price, Japan-US exchange rate, transportation demand, world transportation capacity, freight rate, new shipbuilding price, and second-hand ship price. For oil price, Japan-US exchange rate, and transportation demand, the model applies a binomial lattice model because the three elements are highly uncertain and difficult to estimate future behavior. By generating a bunch of patterns, and optimizing the buy and sell rules, the method considers the uncertainty. From historical data, the average value $\mu$ and standard deviation $\sigma$ are calculated. Based on these values, the model defines the future value $S_{t}$ using Eqs. 1-4. $p$ is probability of rise, $u$ is coefficient when the rise, and $d$ is coefficient when the value falls. $\Delta t$ is a time step of the simulation and rand is a random value $(0-1)$ generated at each time step.

$$
\begin{aligned}
& p=\frac{1}{2}\left(1+\frac{\mu}{\sigma} \sqrt{\Delta t}\right) \\
& u=e^{\sigma \sqrt{\Delta t}} \\
& d=e^{-\sigma \sqrt{\Delta t}} \\
& S_{t}=\left\{\begin{array}{l}
S_{t-1} \cdot u(\text { rand } \leq p) \\
S_{t-1} \cdot d(\text { rand }>p)
\end{array}\right.
\end{aligned}
$$

For the world transportation capacity model, a virtual shipping company representing overall shipping companies is assumed. Because the shipping company executes orders or scraps based on the expectation of future transportation demand, the world transportation capacity is updated in each time step. The detailed procedure is as follows.

(1) Expect transportation demand in $T$ years, $D(t+T)$ by Eq. 5.

$$
D(t+T)=\frac{1}{T} \sum_{M=1}^{T}\left(D(t)+\frac{D(t)-D(t-M)}{M} \times T\right)
$$

(2) If the expected demand exceeds vessel supply in $T$ years, the virtual world shipping company orders new ships to cover the gap. If the gap exceeds the shipyard's capacity, the ship that was to be scrapped will be used temporarily.

(3) If the gap does not exceed the shipbuilding capacity, the company scrap vessels that are over 15 years old.

Our model assumes that the freight rate has a linear relationship with the ratio of transportation demand to world transportation capacity and the price of fuel oil. Freight rate $F(t)$ is defined by Eq. 6. $D(t)$ is transportation demand, $S(t)$ is world transportation capacity, and $O(t)$ is fuel price at time $t$. The parameters $a_{1}, a_{2}$, and $b_{1}$ are obtained by regression analysis using historical data.

$F(t)=a_{1} \times \frac{D(t)}{S(t)}+a_{2} \times O(t)+b_{1}$

Regarding the new shipbuilding price, there are two assumptions: freight rate is a primary factor that affects the price, and the rate has a three-month delay effect on the new ship price. The new ship price $N P(t)$ is expressed by Eq. 7 .

$N P(t)=a \times \frac{D(t-3)}{S(t-3)}+b$

In this model, the freight rate is calculated from the ratio of the transportation demand to the world transportation capacity. Therefore, we use the ratio as a substitute for freight rates.

For second-hand ship price, it is assumed that freight rate is a primary factor of the price, the rate has a three-month delay effect, the price decreases linearly with the age of the ship, and the minimum value is the profit $F$ obtained by scrap. The price $S P(t)$ is defined by Eq. $8 . A(t)$ is the age of the ship.

$S P(t)=\max \left(F,\left(a^{\prime} \times \frac{D(t-3)}{S(t-3)}+b^{\prime}\right) \times\left(\frac{15-A(t)}{10}\right)\right)$ 


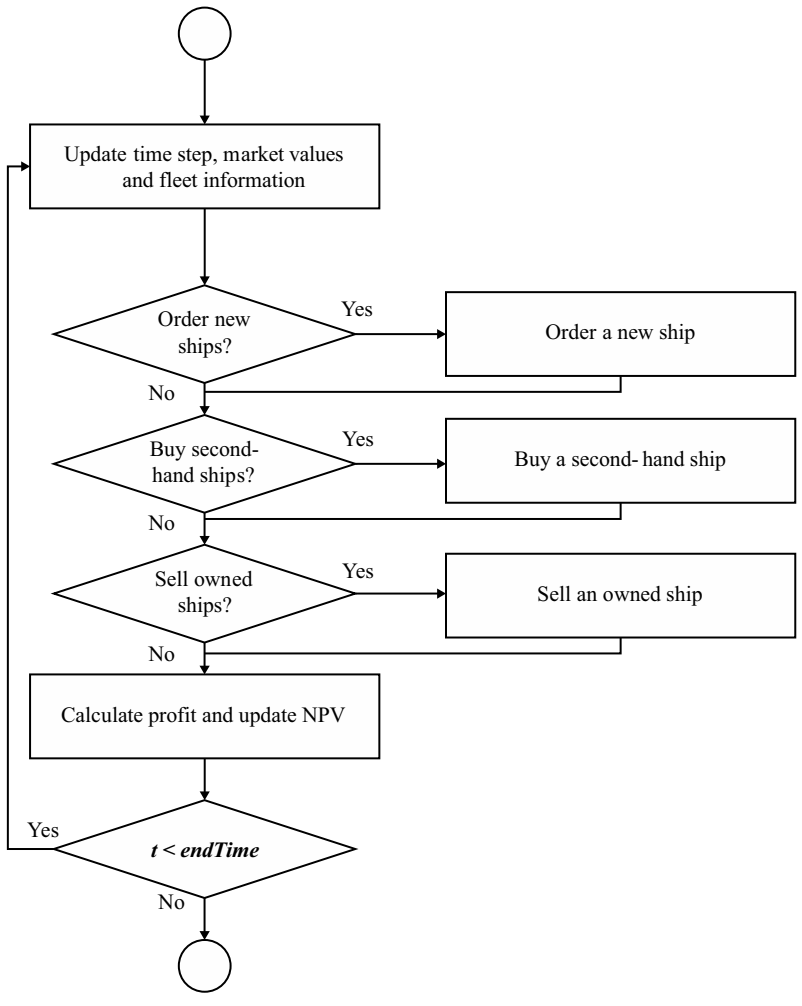

Fig. 2 Flowchart to calculate lifecycle profit of fleet and outputs NPV based on the scenario which is created by the market model

\subsection{Profit calculation model}

This model calculates the lifecycle profit of the fleet and outputs the NPV based on the scenario that the market model creates and buy/sell rules. The procedure is described in Fig. 2.

This is a discrete time-based simulation so that the first step is to update the time step. Based on the time, market values explained in the market scenario and the age of the ships are updated. The procedure has three conditional branches related to the buy/sell rules: order a new ship, buy a second-hand ship, and sell an owned ship. The rules are defined as if-then rules, and the details are described in the next section. If a new ship is ordered, the price and overhead charge are paid. The ship is added to the fleet in $T$ years, which are required to construct the ship. When a secondhand ship is purchased, the price and overhead are charged, and the ship is immediately added to the fleet. When a ship is sold, money, which is equal to the price in the market, is gained, and the ship is removed from the fleet composition.

Next, the model calculates the fleet's profit and updates the NPV. The number of round trips is obtained from Eq. 9. $N D$ is day, which is necessary for a round trip.
$N T=\frac{30 \times \Delta T}{N D}$

Freight income of the round trip is calculated using Eq. 10. $f_{o}, f_{i}(\mathrm{USD} / \mathrm{TEU})$ are the freight for outbound/ inbound trips, $\varepsilon_{o}, \varepsilon_{i}$ are the loading rate, and Size(TEU) is the size of ships.

$I=$ Size $\times\left(f_{o} \varepsilon_{o}+f_{i} \varepsilon_{i}\right)$

Fuel oil consumption rate $F O C(\mathrm{~kg} / \mathrm{km})$ of each ship is estimated by Eq. 11 using ship speed $V(\mathrm{~km} / \mathrm{h})$, displacement $D S P$ (ton), capacity $D W T$ (ton), loading rate $\varepsilon$ and coefficients $k_{c 1}, k_{c 2}$. DSP is assumed by Eq. 12. The fuel cost of the round trip $C_{\text {fuel }}$ is calculated using Eq. 13. $P_{f u e l}$ is the price of the fuel at this time.

$F O C=k_{c 0}\left(D S P-\left(1-k_{c 1} \cdot \varepsilon\right) D W T\right) \times D S P^{-\frac{1}{3}} \times V^{2}$

$D S P=13.7 \times D W T+1660$

$C_{\text {fuel }}=N D \times F O C \times P_{\text {fuel }}$

Because not all the ships in the fleet are operated, the idle rate $\rho$ is introduced. The rate is calculated using Eq. 14. $k$ is the ship volume per unit of demand.

$\rho=\max \left(0,1-k \frac{D(t)}{S(t)}\right)$

Finally, profit is calculated using Eq. 15. $C_{f i x}$ is the fixed cost for a round trip.

Profit $_{\Delta T}=\max \left(-C_{f i x},-\rho C_{f i x}+(1-\rho)\left(I-C_{f u e l}-C_{f i x}\right)\right) \times N T$

Moreover, when the ship's age reaches 15 years, the ship is sold, and the price is added to this profit. By considering the discount rate $r$, the fleet's NPV is updated by Eq. 16 . Profit is a summation of all ships' profit, Sale is cash inflow by selling ships, and Order is cash outflow by ordering new ships or second-hand ships.

$N P V=\sum_{t} \frac{1}{(1+r)^{t}}($ Profit + Sale - Order $)$

\subsection{Optimization with GA}

Using the aforementioned simulation, the sell/buy rules are optimized using the GA. This section explains how the rules are coded into chromosomes, and how an algorithm improves the rules. 
The rules are defined according to the if-then format. For example, a rule to order a new ship is defined by "if $\left(a_{1}<x_{1}<b_{1}\right)$ and $\left(a_{2}<x_{2}<b_{2}\right)$ and $\ldots$, then order 1 ship." The rule can be divided into two parts: the condition part and the execution part. The condition part has five inequalities: fuel oil price, inbound freight, Japan-US exchange rate, number of ships currently owned, and average of inbound freight for 10 months. The assumption that these elements are highly related to decision-making to sell or buy is based on previous research [17-20]. The average of inbound freight for 10 years is considered so as to

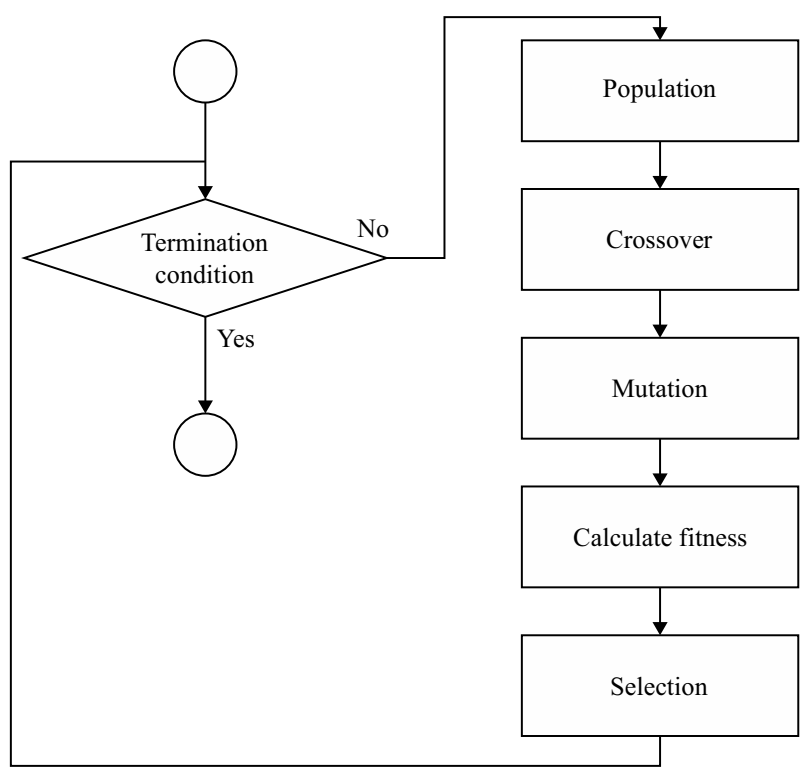

Fig. 3 Flowchart of the GA applied for the optimization of the decision-making rule take the freight rate's periodic characteristic into account. That is, by comparing 10 months' average freight, the rule can consider long-term trends. The five inequalities can be separated into 10 inequalities because each has an upper and lower limit. This means that 10 parameters are necessary to define the condition part. The execution part has only three types: order a new ship, buy second-hand ship, and sell an own ship.

To optimize the rules explained with a GA, the rules should be expressed by a binary vector. In this method, 4-bit binary code is assigned for each inequality. In particular, the reflected binary code is applied for the Hamming distance to be one. The four-bit binary code can express 16 kinds of values. As for fuel oil price, and number of ships currently owned, 15 values in increments of 10, ranging from 0 to 140 , and wildcard are assigned. The wildcard means that there are no applicable conditions for the inequality. As for inbound and outbound freight, and Japan-US exchange rate, 15 values, and wildcards are assigned, which are created from the mean and standard deviation of the generated scenario.

Figure 3 is a flowchart of the GA. The initial population is randomly generated. As genetic operators, crossover, mutation, and selection are implemented. For the crossover, a single-point crossover is applied. Mutation is executed according to probability. For selection, elitism and roulette wheel selection were applied. To calculate fitness, the simulation described in the previous section is utilized. The scenario model generated multiple market scenarios and a profit calculation model output these NPVs. The average score of the NPVs is used for fitness.
Table 1 Parameters for case study

\begin{tabular}{|c|c|c|}
\hline Parameter & Unit & Data setting \\
\hline Payback period & Year & 15 \\
\hline Time step $\Delta T$ & Month & 3 \\
\hline Size of ships Size & TEU & 6000 \\
\hline Route distance $s$ & Mile & 23,179 \\
\hline Ship speed & Knot & 19 \\
\hline Percentage of vessels younger than 5 years old & N/A & 0.254 \\
\hline Percentage of vessels between 5 and 10 years old & N/A & 0.482 \\
\hline Percentage of vessels older than 10 years old & N/A & 0.263 \\
\hline Minimum value of ships $F$ & USD & $3.0 \times 10^{6}$ \\
\hline Discount rate $r$ & N/A & 0.06 \\
\hline Fix cost for operation $C_{f i x}$ & USD/year & $1.84 \times 10^{7}$ \\
\hline Loading rate for outbound trip $\varepsilon_{o}$ & N/A & 0.71 \\
\hline Loading rate for inbound trip $\varepsilon_{i}$ & N/A & 0.31 \\
\hline Delivery period for new buildings $T$ & Year & 2 \\
\hline Capacity of shipyard & Ships/month & 55 \\
\hline Ratio of overhead charge to sell ships & N/A & 0.05 \\
\hline
\end{tabular}


Table 2 Parameters for fuel oil price, Japan-US exchange rate, and transportation demand

\begin{tabular}{llllll}
\hline & $\mu$ & $\sigma$ & $u$ & $d$ & $p$ \\
\hline Fuel oil price & $2.7 \times 10^{-3}$ & $8.6 \times 10^{-2}$ & 1.02 & 9.840 .503 \\
Japan-US exchange rate & $-6.2 \times 10^{-4}$ & $3.1 \times 10^{-2}$ & 1.01 & 9.940 .498 \\
Transportation demand & $3.2 \times 10^{-3}$ & $1.3 \times 10^{-2}$ & 1.00 & 9.970 .522 \\
\hline
\end{tabular}

Table 3 Parameters for freight rate, new and second-hand ship prices

\begin{tabular}{lll}
\hline & $a$ & $b$ \\
\hline Freight rate (outbound) & $2.1 \times 10^{5}\left(a_{1}\right)$ & $-5.3 \times 10^{2}$ \\
& $5.7 \times 10^{1}\left(a_{2}\right)$ & \\
Freight rate (inbound) & $4.0 \times 10^{4}\left(a_{1}\right)$ & $3.1 \times 10^{2}$ \\
& $2.9\left(a_{2}\right)$ & \\
New ships price & $8.2 \times 10^{3}$ & 1.4 \\
Second-hand ship price & $1.9 \times 10^{4}$ & -0.75 \\
\hline
\end{tabular}

\section{Case study}

This study describes a case study to verify each model's behavior and overall procedure in the proposed method. The target ship type is narrowed down into container liner, and the operating route is 23,179 miles between Shimizu in Japan and Southampton in UK. The detailed parameters for the case study are reported in Table 1 . Ship size is fixed at $6000 \mathrm{TEU}$, and the parameters of performance $k_{c 0} k_{c 1}$ are set to $6.87 \times 10^{-5}$ and 0.65 .

For the market scenario model, the parameters of fuel oil price, Japan-US rate, and transportation demand are obtained from historical data, which use monthly oil price data [21], monthly Japan-US exchange rate [22], and monthly transportation demand data [23]. The parameters learned from historical data are presented in Table 2.

Based on the models, parameters of freight rate, new ship price, and second-hand ship price are calculated using regression analysis. For the regression, European container freight date data [24] and ship price data [25] were used. The parameters are listed in Table 3.
Table 5 Parameters for GA in the case study

Crossover probability

Mutation probability

0.8

No. of scenarios

0.05

No. of generations

1000

Size of population

12,000

100

To validate the models, a comparison between generated scenarios and statistics of the historical data is conducted. The results are reported in Table 4 . They are compared with the average, standard deviation, and median. This indicates that the scenarios generated from the model follow the characteristics of the historical data.

Using the simulation setting and market scenario model, the GA optimizes the sell/buy rules for fleet composition. The parameters for the GA are shown in Table 5.

Figure 4 shows the evolution of the fitness score by generations up to 5000. The fitness of generations indicates that the GA works well as an optimization system. Finally, the decision-making rules presented in Table 6 are obtained. For the five variables, fuel oil price, freight rate, average of freight rate for 10 months, Japan-US exchange rate, and number of ships in fleet, upper and lower limits of the decision-making condition are obtained. In the table, wildcards are marked with an asterisk. To validate the usefulness of the rules, a controlled experiment was designed. The details of the experiment and the results are outlined in the next section.

\section{Experiment}

In this section, we conduct a subject experiment to test whether there is a significant difference between the experimental and control groups. Based on the validation, we confirm whether the mined decision rules are effective. In the experiment, the score of the group without the rules is utilized as a baseline to test whether the group with the rules is better. Through a post-experiment survey and data analysis, the mechanism of the advantage of the rules is discussed.

Table 4 Comparison between generated scenarios and Historical data

\begin{tabular}{|c|c|c|c|c|c|c|}
\hline & \multicolumn{3}{|l|}{ Scenarios } & \multicolumn{3}{|c|}{ Historical data } \\
\hline & Ave. & Std. & Mdn. & Ave. & Std. & Mdn. \\
\hline Freight rate (outbound) & $1.3 \times 10^{3}$ & $3.0 \times 10^{2}$ & $1.3 \times 10^{3}$ & $1.4 \times 10^{3}$ & $2.5 \times 10^{2}$ & $1.4 \times 10^{3}$ \\
\hline Freight rate (inbound) & $7.7 \times 10^{2}$ & $1.3 \times 10^{2}$ & $7.4 \times 10^{2}$ & $8.7 \times 10^{2}$ & $1.2 \times 10^{2}$ & $8.5 \times 10^{2}$ \\
\hline World transportation capacity & $4.5 \times 10^{3}$ & $1.1 \times 10^{3}$ & $4.5 \times 10^{3}$ & $4.5 \times 10^{3}$ & $6.2 \times 10^{2}$ & $4.7 \times 10^{3}$ \\
\hline New ships price & $7.4 \times 10^{7}$ & $7.3 \times 10^{6}$ & $7.3 \times 10^{7}$ & $8.1 \times 10^{7}$ & $1.6 \times 10^{7}$ & $7.7 \times 10^{7}$ \\
\hline Second-hand ship price & $6.2 \times 10^{7}$ & $1.7 \times 10^{7}$ & $6.2 \times 10^{7}$ & $6.1 \times 10^{7}$ & $1.8 \times 10^{7}$ & $5.1 \times 10^{7}$ \\
\hline
\end{tabular}




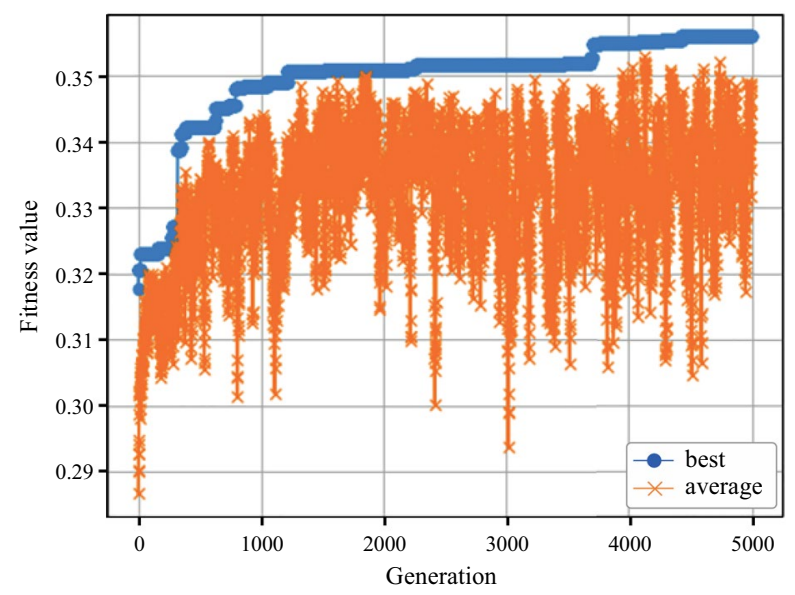

Fig. 4 Evolution of the fitness score of the GA by generations up to 5000
In the control experiment, two groups were prepared and asked to make decisions about the composition of the fleet on an experimental simulator. The experimental group was given the decision rules obtained by the proposed method before starting. On the other hand, the control group was not given the decision-making rules. After having the subjects make decisions about fleet composition on the simulator, the final NPV was recorded. We examined whether there was a significant difference between the results of the experimental and control groups. Welch's t-test was used for testing.

The control experiment requires a simulation in which the subject's decision-making about the composition of the fleet is the input and the NPV is the output. The profit calculation model in the proposed method was utilized. In this method, the decision-making rules are machine processed, and the decisions are automatically executed. On the other hand,
Table 6 Decision-making rules obtained in case study

\begin{tabular}{|c|c|c|c|c|c|c|c|c|c|c|}
\hline & \multicolumn{2}{|c|}{ Fuel oil price } & \multicolumn{2}{|c|}{ Freight rate } & \multicolumn{2}{|c|}{$\begin{array}{l}\text { Ave. of } \\
\text { freight rate for } \\
10 \text { months }\end{array}$} & \multicolumn{2}{|c|}{$\begin{array}{l}\text { Japan-US } \\
\text { exchange rate }\end{array}$} & \multicolumn{2}{|c|}{$\begin{array}{l}\text { \# of ships in } \\
\text { fleet }\end{array}$} \\
\hline & Upper & Lower & Upper & Lower & Upper & Lower & Upper & Lower & Upper & Lower \\
\hline Order a new ship & 30 & 140 & 243 & 2061 & $*$ & 2212 & 0 & 243 & 80 & 140 \\
\hline Buy a second-hand ship & 0 & 140 & $*$ & 2212 & $*$ & 1455 & 54 & 180 & 90 & 120 \\
\hline Sell an own ship & $*$ & $*$ & $*$ & $*$ & 1152 & 2364 & 0 & 264 & 30 & 100 \\
\hline
\end{tabular}

Compare with data

UI of the simulator three months ago

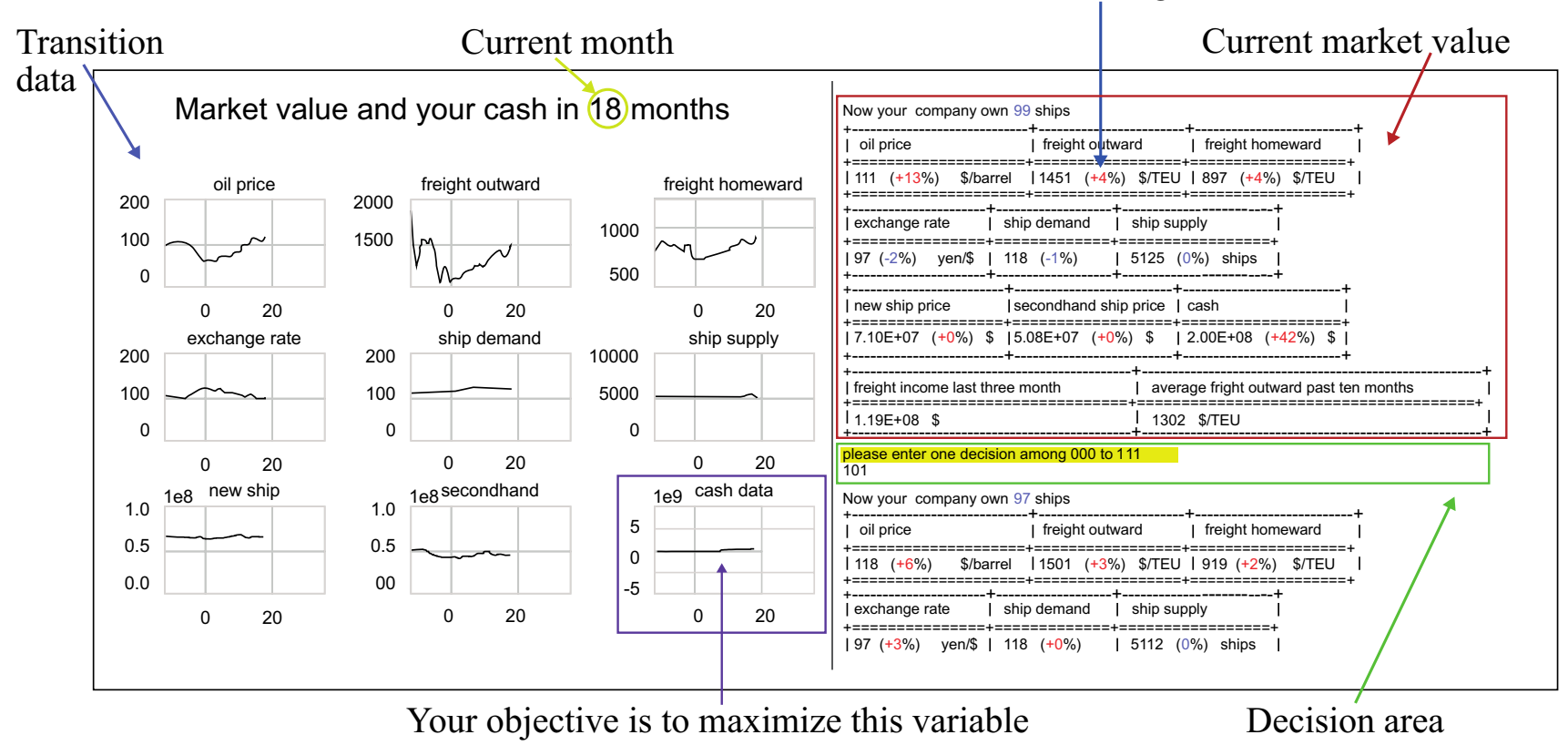

Fig. 5 User interface of the simulation for the experiment 
Table 7 Final profit scores of subject experiments $\left(\times 10^{11} \mathrm{JYP}\right)$

\begin{tabular}{|c|c|c|c|c|c|c|c|c|}
\hline \multirow[b]{2}{*}{ ID } & \multicolumn{4}{|c|}{ Experimental group } & \multicolumn{4}{|c|}{ Control group } \\
\hline & A & B & $\mathrm{C}$ & $\mathrm{D}$ & $\mathrm{E}$ & $\mathrm{F}$ & G & $\mathrm{H}$ \\
\hline Pattern 1 & 0.60 & 0.55 & 0.12 & 0.59 & -0.25 & 0.17 & 0.14 & 0.41 \\
\hline Pattern 2 & 3.37 & 3.40 & 3.13 & 3.27 & 2.89 & 2.80 & 2.92 & 2.90 \\
\hline Pattern 3 & 4.57 & 4.71 & 4.63 & 4.63 & 3.66 & 3.55 & 3.28 & 2.96 \\
\hline Average & 2.85 & 2.88 & 2.63 & 2.83 & 2.10 & 2.18 & 2.11 & 2.09 \\
\hline
\end{tabular}

all the decision-making was conducted by the subjects in the experiment. Four subjects were assigned to each group.

The user interface (UI) of the simulator is shown in Fig. 5. It shows how the subjects of the experiment obtained the information and how they entered their decisions. The left side of the UI shows the transition of the market and the company's profit. Based on this information, the subjects operate the right side of the UI and make a decision on buying or selling ships. The subjects play the simulator with the same three scenarios called Pattern $1 \sim 3$, generated by the market model.

The results of the experiment are reported in Table 7, which presents the final scores and the average of each subject. The table shows final profit $\left(\times 10^{11} \mathrm{JPY}\right)$ of the experimental and control group. ID means the subjects' ID belonging to each of the groups. Three scores in pattern $1 \sim 3$ of each subject, and an average of the scores is shown in the table. Using the data and testing them with Welch's t-test, it indicates that there is a significant difference between them. The p-value is $5.0 \times 10^{-4}$. This means that the group with the rules set by our method obtained better scores than the group without the rules. In particular, the results indicated that the final score of the experimental group with the rule improved by about $30 \%$ compared to the control group without the rule.

Figure 6 shows the transition of cash flow over time for each scenario. The gray lines show each subject's cash flow, the orange line is the average of the controlled group without the rules, and the green line is the average of the experimental group with the rules. All the graphs show the same trend. That is, in the initial phase of the operation, the experimental group's cash flow is significantly negative, and then recovers over time, resulting in better results than those of the control group. It is suggested that in contrast to the rule strategy of continuing to invest with a long-term perspective, the control group focused on relatively short-term returns, which is the reason for the difference in final returns.

\section{Discussion}

This study suggests that the method using simulation and heuristic optimization methods can determine decision-making rules for fleet composition management, which leads to better decision-making in the uncertain shipping market.
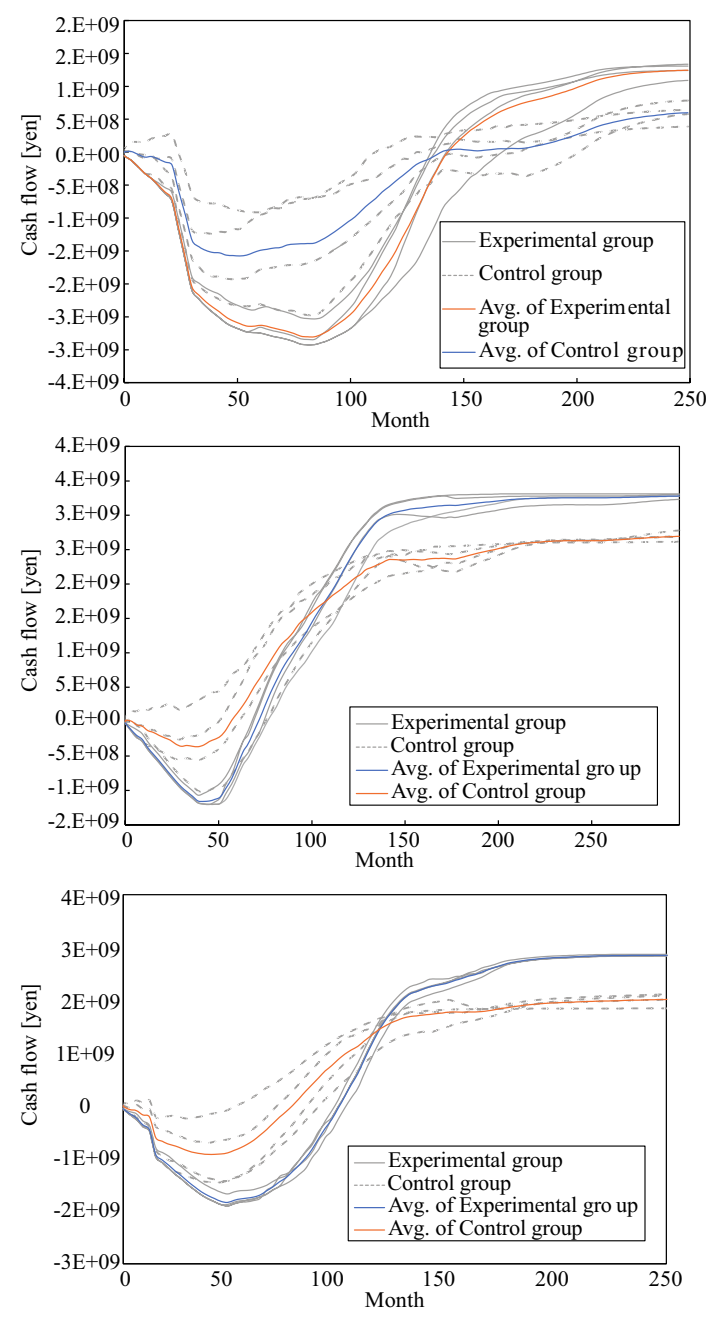

Fig. 6 Transition of the cash flow over time for each scenario in the experimental (Pattern 1-3)

The results indicate that the rules determined by the method are able to overcome human intuition in decision-making. The average scores of the experimental group and the control group are 2.80 and 2.12 , respectively, indicating that the proposed method improves the scores by about $30 \%$. It also shows that the rules can reduce individual differences by clarifying the criteria for decision-making. By comparing the transitions of cash flow of each group over time, it 
is suggested that the group with the rules can make a decision with a long-term perspective, and it leads to better performance.

This study has several limitations. This experiment included only eight subjects. This study applied Welch's t-test where the one-sided significance level was $2.5 \%$ and the power was 0.8 . However, previous research [26] suggests that 52 subjects are needed for the test. To show more rigorous statistical significance, it is necessary to conduct experiments with more subjects. The simplicity of decisionmaking rules is another limitation in that the condition part only relates to fuel oil price, freight rate, Japan-US exchange rate, and fleet size, and the execution part contains order a new ship, buy a second-hand ship, and sell an own ship. Regarding the condition part, it is necessary to consider other elements that affect decision-making. The execution part does not consider chartering a ship. More detailed modeling is needed to make the rule more realistic. The validation and calibrations of the model by comparison with the actual dataset is also another important work. In this paper, the binomial lattice model is applied for the market scenario model. More detailed modeling is possible by combining knowledge of market behavior from previous work, and the validation using the actual dataset is useful to confirm the model's improvement.

For future work, a comparison between the rules revealed by this study and expert tacit knowledge is of interest. By comparison, whether the rules have any common part with the experts, whether the rules can bring new awareness to the experts, and what factors are missed in the rule can be identified. Moreover, whether some differences occur between experts with and without rules may be an interesting research question. An application of other methods of optimization and mining rules is another future work to improve the research. Real coded GA [27] and many other non-linear optimization techniques are applicable for the problem framed by this study, and exploration of which method performs the best is necessary to improve this study.

\section{Conclusion}

This study describes a method for discovering decision-making rules on fleet composition that are effective from a profitability perspective under market uncertainty. Using simulations and GA to optimize the buying and selling behavior of ships enables the discovery of decision-making rules of fleet composition. As a case study, the method was applied to container ships operated between Asia and Europe. This method revealed decision-making rules that were optimal in the simulation. Moreover, a controlled experiment was conducted to validate the effectiveness of the rules. In the experiment, participants were randomly divided into two groups, those with the rules and those without, and they were asked to perform buying and selling behavior in the simulation. Compared to the control group, the final score of the experimental group improved by approximately 30\%, and the result of Welch's $\mathrm{t}$-test indicated that the difference was significant. Analysis of the experiment's data revealed that the rules encouraged decision-making from a long-term perspective, which led to a better score under market uncertainty.

Open Access This article is licensed under a Creative Commons Attribution 4.0 International License, which permits use, sharing, adaptation, distribution and reproduction in any medium or format, as long as you give appropriate credit to the original author(s) and the source, provide a link to the Creative Commons licence, and indicate if changes were made. The images or other third party material in this article are included in the article's Creative Commons licence, unless indicated otherwise in a credit line to the material. If material is not included in the article's Creative Commons licence and your intended use is not permitted by statutory regulation or exceeds the permitted use, you will need to obtain permission directly from the copyright holder. To view a copy of this licence, visit http://creativecommons.org/licenses/by/4.0/.

\section{References}

1. Stopford M (2008) Maritime economics. Routledge

2. Matagawa K, Tanaka K, Akimoto H, Miyata H (2008) A study on market prediction model based on fleet demand trend. Proc Jpn Soc Naval Architect Ocean Eng (In Japanese) 6:437-438

3. Everett JL, Arnoldo CH, Lewinson VA, Nudds D (1972) Optimization of a fleet of large tankers and bulkers: A linear programming approach. Marine Technol SNAME News 9(4):430-438

4. Murotsu Y, Taguchi K (1975) Optimization of ship fleet-size. Bull Univ Osaka Prefecture Series A, Eng Nat Ural Sci 23(2):177-192

5. Zeng Q, Yang Z (2007) Model integrating fleet design and ship routing problems for coal shipping. In: International Conference on Computational Science. Springer Berlin Heidelberg, pp1000-1003

6. Darzentas J, Spyrou T (1996) Ferry traffic in the aegean islands: a simulation study. J Operational Res Soc 47(2):203-216

7. Xie X, Wang T, Chen D (2000) A dynamic model and algorithm for fleet planning. Marit Policy Manag 27(1):53-63

8. Meng Q, Wang T (2011) A scenario-based dynamic programming model for multi-period liner ship fleet planning. Transp Res E: Logist Transp Rev 47(4):401-413

9. Jin D, Kite-Powell HL (2000) Optimal fleet utilization and replacement. Transp Res E: Logist Transp Rev 36(1):3-20

10. Alvarez JF, Tsilingiris P, Engebrethsen ES, Kakalis NM (2011) Robust fleet sizing and deployment for industrial and independent bulk ocean shipping companies. Info Syst Operational Res 49(2):93-107

11. Pantuso G, Fagerholt K, Hvattum LM (2014) A survey on maritime fleet size and mix problems. Eur J Oper Res 235(2):341-349

12. Bendall HB, Stent AF (2004) Ship investment under uncertainty: a real option approach. University of Otago Department of Finance Seminar Series 
13. Fidelis MV, Lopes HS, Freitas AA (2000) Discovering comprehensible classification rules with a genetic algorithm. In: Proceedings of the 2000 Congress on Evolutionary Computation. CEC00 (Cat. No.00TH8512), 1:805-810 vol.1

14. Kim MJ, Han I (2003) The discovery of experts' decision rules from qualitative bankruptcy data using genetic algorithms. Expert Syst Appl 25(4):637-646

15. Adland AO, Koekebakker S (2004) Market efficiency in the secondhand market for bulk ships. Marit Econ Logist 6(1):1-15

16. Alizadeh $\mathrm{AH}$, Nomikos NK (2007) Investment timing and trading strategies in the sale and purchase market for ships. Transp Res B: Methodological 41(1):126-143

17. Menachof D (1996) Risk management methods for the liner shipping industry: the response to customer service demands for simplified tariffs. J Bus Logist 17(1):259-290

18. Menachof DA, Dicer GN (2001) Risk management methods for the liner shipping industry: the case of the bunker adjustment factor. Marit Policy Manag 28(2):141-155

19. Ådland R, Jia H (2008) Charter market default risk: A conceptual approach. Transp Res E: Logist Transp Rev 44(1):152-163

20. Fan L, Luo M (2013) Analyzing ship investment behaviour in liner shipping. Marit Policy Manag 40(6):511-533
21. U.S. Energy Information Administration, Spot prices for crude oil and petroleum products, https://www.eia.gov/dnav/pet/pet_pri_spt_ s1_d.htm. Accessed 30 Jan 2020

22. Bank of Japan, Key time series statistics table (in Japanese), https:// www.stat-search.boj.or.jp/ssi/mtshtml/fm08_m_1.html. Accessed 30 Jan 2020

23. CPB Netherlands Bureau for Economic Policy Analysis, World trade monitor https://www.cpb.nl/en/worldtrademonitor. Accessed 30 Jan 2020

24. Japan Maritime Sector, Past reports on the European container route (in Japanese), http://www.jpmac.or.jp/relation/european_container. html. Accessed 30 Jan 2020

25. Jeon JW, Yeo GT (2017) Study of the optimal timing of container ship orders considering the uncertain shipping environment. Asian J Shipping Logist 33(2):85-93

26. Cohen J (2013) Statistical power analysis for the behavioral sciences. Academic Press

27. Wright AH (1991) Genetic algorithms for real parameter optimization. Foundations of Genetic Algorithms 1:205-218

Publisher's Note Springer Nature remains neutral with regard to jurisdictional claims in published maps and institutional affiliations. 